\title{
Research on Unique Course System for Low-carbon Talent Cultivation Xingjia Liu ${ }^{1, a}$ \\ 'Department of Thermal Energy and Power Engineering Harbin University of Science and Technology Harbin, China \\ axj3333333@sina.com
}

\author{
Keywords: Low-carbon; Wide caliber talent training; Professional platform; Characteristic \\ curriculum system; Education reform
}

\begin{abstract}
In this paper, the purpose is to explore how to establish a characteristic and competitive curriculum system which is suitable for low-carbon talent cultivating, to adapt to the changing market demand for low-carbon talents; the methods is to analyze the importance, opportunities and challenges of the low-carbon talent market; to study the necessity and difficulties of the cultivation of large-caliber talents and the relationship between the cultivation of large-caliber talents and insisting features. Results are that the requirements of the characteristic curriculum system and their influencing factors were found, and the requirements and approaches of establishing the characteristic curriculum system for low-carbon talents were obtained; the content and mode of curriculum system with a wide caliber and characteristics have been proposed. The conclusion is that the scientific feature course system is important for the low-carbon talent training, which will certainly play an important role in the competition of talent training.
\end{abstract}

\section{Introduction}

With the continuous economic globalization, the rapid development of social economy is restricted by energy and environment, and the competition is increasingly fierce. How to solve the problem of energy shortage and environmental change is urgent. The people of vision in the world are vigorously promoting and pushing forward the low-carbon economy $[1,2]$.

However, developing a low-carbon economy is a very difficult task. It needs a long way to go and requires high-level technical talents. Colleges and universities are important bases for cultivating high-level technical talents. They must shoulder the important task of cultivating low-carbon talents. The energy majors closely related to the low-carbon must be at the forefront of cultivating low-carbon talents. On the one hand, the social needs of low-carbon talents have opened up a broader market for student employment. On the other hand, the talent demand for the social development is higher and higher, and the competition in the talent market is more and more intense.

In order to win in the talent market competition, the colleges and universities must adjust the professional structure and training mode. The cultivated talents should have strong self-adjustment ability, can engage in a variety of occupations, and can be accepted by the market.

In this paper, based on the analysis of the talent market prospects and the talent cultivation strategy, combined with the actual situation of our country's majors of energy and power engineering, the course system suitable for low-carbon talent training be studied and explored. The course system not only has wide adaptability and distinctive features, but also helps students to develop low-carbon ideas and knowledge structure. The results of the study can be applied to low-carbon talent training of compound application type. The results can also be used as a reference for other related majors.

\section{Necessary, Difficulties and Train of Thought to Establish a Large-caliber Talent Training Platform with Distinctive Features}

Necessary. In order to realize the rapid and sustainable development of the country's economy [3], low-carbon economic development model must be realized, and a large number of talents with low 
carbon concept and knowledge structure are needed. It is an effective guarantee for the sustainable development of national economy, which has important strategic significance.

Colleges and universities expand the enrollment scale, and realize the transformation from the elite education to the popular education, which plays an important positive role in meeting the needs of low carbon society and improving the overall quality of our national people.

However, with the expansion of enrollment scale, the employment contradiction is highlighted due to the unbalanced economic growth, and the constraints between social demand and the development of higher education. The employment situation of college students is becoming more and more serious, and they face the unprecedented employment pressure. Employment difficulty has become one of the outstanding problems in our higher education. Colleges and universities are bases for training advanced talents, and the students must have the ability to serve society. Therefore, in a certain degree, the modern higher education continuously increases market factor and participates in market operation [4]. In the background of increasing enrollment and popularization of education and employment difficulties, it is difficult to establish a foothold in the competition of talent cultivation if universities have no distinctive features and advantages.

In order to meet the changing demand of market economy, since reform and opening up, the goal of talents training in colleges and universities in China has changed from cultivating "red and special" to cultivating "thick base and big caliber". The structural imbalance between market demand and talent supply is always accompanied. There is a contradiction between the target of "thick foundation and the big caliber" and the professional requirement. Therefore, under the new situation, the universities and their majors must possess the diversification of talents training target [5], must establish a professional talent training platform which is suitable for their own conditions and characteristics, has characteristic and competitiveness, and Meets the requirement of low-carbon talent training.

Difficulties. It is undoubtedly necessary to broaden the professional caliber and cultivate high quality talents with wide adaptability, which is one of the important tasks of higher education reform. There are several main conflicts in the following aspects:

The first is the contradiction between the change and diversity of social needs and the relative stability and lag of university talent training.

The second is the contradiction between the particularity of talent social demand and the universality of talent cultivation in colleges and universities.

The third is the contradiction between the wide range of employment and the technicality of talent training.

From the perspective of student employment, on the one hand, a broad talent training model is conducive to increasing the employment scope of students, but on the other hand, employers want students to be as professional as possible. How to solve this contradiction becomes the focus problem of cultivating talents in colleges and universities [6].

The goal of cultivating talents in colleges and universities is to provide a variety of talents for the construction of the country to enables our country to create a strong competitiveness under the conditions of integration with the global economy. Colleges and universities must run schools in various industries, but not in a single industry. They are required extensive teaching. But at the same time, they must be careful not to overstate the significance of "common sense" education. We simply cannot achieve the so-called generalist culture. The results disjointed the talent training and industry needs, and made the pertinence of talent training and scientific research much less. Which will not only affect students' employment, but also severely affect the competitiveness of education institutions and influence their development and even survival. In order to solve these problems, we should focus on the following aspects:

The first is to make a difference and find the exact location [7]:

For a high level of key university, their professional caliber of talent training can be wider than normal school, which can not only lay a good foundation for the graduate students, can also b open up a broader employment way for their students with their reputation advantage. 
For the relatively low level of ordinary institutions, the professional caliber in talent cultivation should be smaller. They should mainly consider professional dialogue, so that the graduates can get the job as soon as possible.

In one word, Professional positioning relates to the success or failure of talent cultivation. Professional positioning should be accurate and characteristic, to form a complete scientific system.

The second is to adopt a variety of training modes to achieve diversified training objectives:

From the needs of the talent society, the society needs talents: technical talents and compound talents.

From education itself, education has various forms and types. This diversity embodies the diversity of training objectives, the diversity of quality standards, and diversity of training patterns.

The diversity of training objectives helps to pinpoint targets. There are obvious differences in research, technology, compound and other training objectives. We should adopt different training modes. Therefore, according to different talent training objectives, different training modes can be used to fully meet the diversification of social needs and achieve the diversification of training objectives. It is of great significance to improve the competitiveness of college talents.

\section{Feature of Unique Course System Adapted to Low-carbon Talent Training and Its Structure Ideas}

The strong support for the goal of talent cultivation is the curriculum system [8]. It should be a wide professional and distinctive course system [9]. It is the key and difficult point of education reform in colleges and universities. This is because the wide professional caliber course system must cover the main content of the original majors. Therefore, the curriculum system of large-caliber professional platforms should not be limited to original professional content, nor should it be constructed into a "cold dish put together" of several original professional contents. Therefore, the curriculum is not a simple multi-direction superposition. It must have a qualitative leap. Obviously, this is very difficult without adding class time. The successful establishment of the professional curriculum system will have a great impact on the success or failure of the education reform. Therefore, the realization of teaching curriculum objectives cannot depend solely on the curriculum system itself. It should be carried out with comprehensive curriculum system reform, teaching method reform, teaching material construction and supporting mechanism of school.

Here, we present the composition of the course system (see table 1) and design ideas [10].

Table 1 course system and its function

\begin{tabular}{|l|l|}
\hline \multicolumn{1}{|c|}{ course system } & \multicolumn{1}{c|}{ function } \\
\hline $\begin{array}{l}\text { professional } \\
\text { platform course } \\
\text { system }\end{array}$ & $\begin{array}{l}\text { 1 Broaden the professional caliber to meet the diversified demand of the } \\
\text { talent market } \\
\text { 2 Adapt to the knowledge structure requirement of low carbon talent, } \\
\text { 3 Reflect characteristics }\end{array}$ \\
\hline $\begin{array}{l}\text { professional } \\
\text { direction course } \\
\text { system }\end{array}$ & $\begin{array}{l}\text { 1 Meet the talent needs of specific industries } \\
\text { 3 Improct the characteristics of the professional direction: }\end{array}$ \\
$\begin{array}{l}\text { professional elective } \\
\text { courses system }\end{array}$ & $\begin{array}{l}\text { 1 Perfect low-carbon knowledge structure } \\
\text { 2 promote the development of students personalities }\end{array}$ \\
\hline
\end{tabular}

Establishing a Wide Caliber and Professional Platform Course System with Characteristics. It can lay a solid foundation for the wide spread of talent training to broadening the professional caliber and to expand the knowledge of students. Insisting on characteristic education can improve students' social and international competitiveness. 
To expand the professional caliber effectively, we must build a series of courses, namely the so-called professional platform curriculum system which needs to cover the content of the original professional courses. Specific courses should be set up, different schools should be based on their own development history, advantages and actual situation. The platform curriculum system should reflect their characteristics and advantages.

It should be noted that in the content selection, the course system cannot form a simple "cold dish put together" of the original professional content, which must have a qualitative leap. It not only expands the professional range, but also differs from other colleges and universities. It should reflect their characteristics. It can be closely related to social needs and can stand at the forefront of industry development [7].

Establishing and Improve Characteristic Professional Direction Course System of Modules. At the same time of widening specialty caliber, in order to meet the social demand for specific professional talents, to improve students' competitiveness in the talent market, the course system must contain a number of relatively perfect professional direction course modules for students to take, so that the students can grasp the direction of the major professional knowledge systematically. At the same time, the establishment of a professional course system should be commensurate with the scale of the school, should give full play to the advantages of school resources, and should combine with market demand.

Colleges and universities should timely adjust and constantly improve their own professional direction course system, and always maintain their own distinct characteristics.

Elective Courses Can Promote Development of Students' Personalities. Elective courses in the field should be provided in the course system. Based on their own interests and career plans, students can choose elective courses that they like. This can promote students' personality development. And these elective courses can also well reflect characteristics.

Practice Course System and Theoretical Cour se System Complement Each Other. Combining practical teaching can help theoretical teaching and improve students' innovation ability; It is an important task of education reform to strengthen students' ability and improve their quality. Students' practical ability and innovation ability are closely related to the practice teaching curriculum system. Practical teaching will play a huge and irreplaceable role in the overall talent cultivation of the ability of application and innovation. Therefore, in the teaching plan, the time and content of practice teaching should be increased appropriately. For example, curriculum design, internship, graduation design, computer application, and the proportion of skills training, etc should be appropriately increased, in order to increase the depth of the student understanding of knowledge, improve their ability to use knowledge to solve practical problems. At the same time, it can also help to improve the effectiveness of theoretical teaching, especially for solving teaching problems after professional platform development.

Practical teaching and theoretical teaching are complementary.

Integration of Curriculum System. The curriculum system is a complete system of interrelation and reinforcing each other. It is difficult to make basic courses, professional platform courses, professional direction courses and major elective courses to form distinctive features. The prominent contradiction is to broaden the professional scope and improve the application ability. In a limited class, it is impossible to teach through and through. But that doesn't mean you can reduce the quality of your teaching. The starting point of the education reform is to realize the transformation from simple imparting knowledge to imparting knowledge, improving ability and improving quality. It will undoubtedly make teaching more difficult. In order to solve this problem, the content of the course must be integrated on a multi-dimensional scale to make the curriculum system scientific, so that their various parts can penetrate into each other, to make them be complement each other and integrate. At the same time, the concept of teachers must change. Only by strengthening the construction of the teachers' team, improving the textbook reform, reforming the teaching method, perfecting the teaching facilities and other comprehensive education teaching reform, the reform of curriculum system can be effective.

Of course, the completion of these reforms has considerable difficulties, some of which need to be studied and explored. Therefore, the establishment of a special curriculum system cannot be isolated and must be coordinated with other higher education reforms. 


\section{Summary}

Developing a low-carbon economy is the only way to achieve sustainable economic development. Low-carbon economy brings opportunities to colleges and universities, but also challenges. On the one hand, the low-carbon economy is in urgent need of relevant talent, On the other hand, a low carbon economy may cause a significant number of industries to fail, leading to structural unemployment.

In the context of expanding the enrollment scale and realizing the popularization of education and the difficulty of employment, Colleges and universities want to have a place in the competition, they have to establish and perfect their distinctive curriculum system, which is related to their survival and development.

The $t$ energy professionals should be at the forefront of the cultivation of low-carbon talents. Through the research and exploration of the distinctive curriculum system, we can meet the demand of increasing market demand to improve the competitiveness of talent training.

Of course, the post-reform course system is more difficult to operate. The improvement of its application results still requires a great deal of effort. It is reasonable to believe that with the continuous deepening of the reform of education and the establishment of scientific operation mechanism, a complete system of characteristic courses will play an important role in the talent training of higher education.

\section{Acknowledgements}

The project was sponsored by the Heilongjiang High Education Institute (HGJXHb1110521) and thanks them, also thanks for the help from my colleagues.

\section{References}

[1] Y.T. Xu,W.Liu and Q.Z.Zhang: Chinese Journal of Nature, Vol 33 (2011) No. 2,p.81.

[2] T. Guo and F.L.Sun: Economic Forum, (2016) No. 7, p.79.

[3] T.Yu and Y.N.Guo: Social Sciences Review,( 2013) No.12, p.26.

[4] Y.Li: China Economic \& Trade Herald,(2015)No.13,p.63.

[5] Z.J.Zhang,W.H.Xu and S.N.Li: Journal of Baicheng Normal University, (2012)No.5,p. 177.

[6] J.L.Song: Journal of Henan Institute of Science and Technology, (2013) No. 8, p.12.

[7] T.E.Shen: Journal of Higher Education Finance, Vol 17(2014 )No.2. p.13.

[8] H.X.Zhao and H.Y.Yu: Science \& Technology Information, Vol 13(2015)No.7, p.171.

[9] G.H.Xue,N.F.Xiong and L.H.Zeng: Education Teaching Forum, (2016)No.51,p.156.

[10] M.Yang,Z.Xu,Y.J.Hu and Y.J.Zhong:L.Song: Higher education journal,(2015)No.14,p.4. 